\begin{abstract}
S
FURTHER notes of the papers and discussions at the Copenhagen Congress (principally from the Zentralblatt f. Hals-, Nasen-, und Ohrenheilkunde, 1928, Vol. xiii., pp. 34-64).

Abstracted by F. W. Watkxn-Thomas.
\end{abstract}

EAR

Researches on the Pneumatisation of the Temporal Bone.

K. Eisinger (Vienna).

Eisinger's material consisted of $\mathrm{I} 6$ patients aged from two to eighteen months of age in whom an undoubted otitis media had led to a periosteal abscess that required operation. Twelve of these patients were under a year old at the time of operation. Six years after the operation, skiagrams of the temporal bone were taken; the results were as follows:-

In seven of the mastoid processes pneumatisation was complete or nearly complete; two showed a moderate degree of pneumatisation; in the remaining seven pneumatisation was normal only in some parts. Of these seven children, six had been operated on in the first year of life. In the majority of these well-pneumatised temporal bones there is a mucous membrane that during the first, or at any rate in the earliest stages of the second, developmental period of pneumatisation has been subjected to a severe otitis; in spite of that, taken over the whole series, the pneumatisation has not been affected as one would have expected to happen on the rules that Wittmaack has himself laid down. It still remains doubtful, therefore, how the degree of pneumatisation in these cases can be explained on Wittmaack's recent hypothesis as due to condition or type.

In the discussion, Von Eicken said that if skiagrams were taken systematically of all cases, it was not uncommon to find in the same patient complete pneumatisation on the one side and complete absence of celis on the other. Such a cell arrangement was not consonant with individual or constitutional peculiarity, but it could be easily explained on the assumption that the absence of cells on the one side was due to inflammation. He would like to ask Dr Eisinger whether he had ever seen cholesteatoma develop in any of these cases of pneumatisation after mastoid operation in early childhood. He would regard it as unlikely.

Fraser, referring to the classical research of Arthur Cheatle, pointed out that, although the work was published in London in 1907 , it had still received no adequate recognition on the continent of Europe.

voL. XLIV. No. VIII.

553

20 


\section{Abstracts}

Summarising Cheatle's work, the speaker drew special attention to the clinical aspects. Here Cheatle had laid stress on the fact that in the well-pneumatised type of temporal bone an acute mastoiditis runs a milder course; in the sclerotic type it may either heal spontaneously or set up complications, labyrinthine or intracranial, or may become chronic. Of these possibilities the last is the most frequent, hence in cases of chronic suppuration operation usually reveals a sclerotic type of mastoid. In other words, the sclerosed mastoid is the cause, not, as is usually now stated, the effect of a chronic suppuration.

Von Gilse regretted that Professor Wittmaack was not there to deal with the objections that had been raised. As a result of his own researches on the pneumatisation of the nasal accessory sinuses, the speaker, on the whole, had come to similar conclusions as to the cause of failure of pneumatisation. Wittmaack himself had shown in this connection that there were still other factors in the condition of the bones that might play a considerable part in pneumatisation. Quite apart from rickets, it is unquestionable that a whole series of the diseases of early life can injure the bony structure. It is probable that the question as to how, in the same case, by the arrest of the process the bone can be sclerotic on the one side and spongy on the other, can be answered by examination of the condition of the bone when the process of arrest commences. As an example of a condition, in some respects generalised, which influences pneumatisation, he would quote mongoloid idiocy, in which pneumatisation of the sphenoids and frontal bones is arrested, since the bony changes that occur, although limited in time, occur at the time when these cavities develop in the bone; the maxillary sinus and the temporal bones in such cases usually attain normal development. Further, he would make these practical deductions from Wittmaack's teaching, that in opposition to the older school of pediatrists the treatment of otitis in very young children was of the utmost importance in order to prevent deleterious influences on the development of the bone.

Schüller mentioned, as examples of bone disease which involved an arrest of pneumatisation, dyostosis cleido-cranialis and ivory exostosis; in the majority of cases of acromegaly pneumatisation was exaggerated; pneumatisation in rickets showed no characteristic change.

Goerke said that in spite of all the undoubted objections to Wittmaack's view, it had the great advantage of drawing attention to hitherto neglected anatomical principles. Eisinger's cases could not be used in support of these objections, since in these cases the mucous membrane was restored to normality by the original operation and so could carry out its pneumatisating functions unchanged. There was, 


\section{Ear}

however, a great difficulty in the impossibility of explaining on these lines why, in spite of the frequency of intrapartum tubal infection with its influence on the production of arrest of mucous membrane pneumatisation, only a relatively small percentage of cases of such arrested pneumatisation were found in later life.

Neumann could only say that he did not regard Wittmaack's view with sympathy. They had heard too the results which his assistant Dr Eisinger had obtained and the facts that he had so clearly stated. He agreed with Goerke that Wittmaack's teaching offered a new point of view. The structure of the mastoid process and the course of acute otitis media had been a matter of great interest to him for a long time. He had discussed it in the fourth edition of Politzer's Hand-Book, and also in the discussion at Bremen in 1907 .

Kümmel reported a case of acromegaly in which he had had to perform an antrotomy. Under an extraordinarily hard and thick layer of bone there was found a single cell cavity of unusual size with retained pus. The mastoid process was not unduly large.

S. H. Mygind said that on the correctness of Mouret's and Wittmaack's teaching to-day there could be hardly any doubts. The clinical evidence in their favour was very strong, but how on Wittmaack's view did the observed abnormalities of the middle-ear mucous membrane arise? That the penetration of the amniotic fluid played a predominating part seemed improbable. Clinical observations had led him to the following conclusions:-The fluid content of the organism is physiologically at its greatest in the beginning of life; later it undergoes continual diminution. Correspondingly in the ears we found the myxomatous fotal mucous membrane type that in the course of growth continually diminished. In little children, amongst other things, the subcutaneous tissue was very abundant. Later on that too was reduced, to a slighter extent in women, but much more so in men. Under various recognised conditions of disease this physiological reduction was arrested, as well in the ear as in the subcutaneous tissue, so the tissue could increase its water content. In the middle ear this condition is manifested by persistence of fœtal mucous membrane-Wittmaack's hyperplastic type. In time this can give rise to secondary conditions. Such mucous membrane can undergo more or less fibrous change-the hypoplastic type. In the same individual very often subcutaneous and cellular œdema is found as a pathological increase of the physiological deposition of water in the cells arises. A recurrent or chronic middle-ear suppuration not uncommonly appears as an isolated disease, particularly clearly we see this in young children. They suffer from rickets, bronchitis, dyspepsia, anæmia, tuberculosis, etc. Many of these extra-aural 


\section{Abstracts}

manifestations of disease are probably connected with cellular œdema. This abnormal water deposition is a consequence of a disordered function of the capillaries. Whether ear, lung, or gut bears the brunt of the diseased process depends on a local disposition, some locus minoris resistentice, which, as the history of these patients shows, is frequently hereditary. Further, local disease brings about also a diminution of local resistance. The whole condition of the patient, particularly of the vasomotor regulation, is of considerable significance. Here too we are concerned with a group showing an inborn vasomotor lability, and a group with other factors; and lastly with a group due to unsuitable ways of life and post-infective intoxications. The vitality of such diseased mucous membrane is naturally lowered, its resistance against infection is slight. Infection recurs and becomes chronic. The function of injured tissue is lowered. Thus then pneumatisation, in part at least recognised as a function of the middle-ear mucous membrane, is checked or abolished in these cases.

Portmann in his reply referred to the work of Cheatle and the remarks of Mygind.

Eisinger in his reply said that cholesteatoma was not found in any of the cases.

\section{Otitis due to Plugging of the Nose and Nasopharynx. T. German (Budapest).}

In a series of 28 cases seen in the last ten years, the author has established a definite relationship between nasal plugging and acute middle-ear suppuration. The otitis secondary to nasal plugging is caused in two ways, according to the position of the plug in the anterior or posterior region of the nasal fossæ. In the posterior cases the acute otitis is due to a direct ascending infection through the tubal orifice; German believes that in the anterior cases the route of infection is by the lymphatic track of the nose, nasopharynx and tubal mucosa. The duration of the period of plugging does not seem to exert much influence on the production of acute otitis media.

The clinical characteristics are severe early symptoms, a prolonged course, and a favourable prognosis. It is remarkable that, considering the frequency of epitympanic invasion, in only 4 cases out of 28 was operation necessary; moreover, in 2 cases where intracranial complications occurred there was complete cure.

With regard to the bacteriological examination in the whole series no case was found of influenzal infection, and staphylococcus was not common. The most striking features of the bacteriological results were the predominance of Streptococcus hamolyticus, the frequent appearance of pneumococci, and the prevalence of primary mixed infections. 


\section{Ear}

\section{The Ocular Reflexes in Rabbits produced by Artificial Currents in the Semi-Circular Canals. P. Juan Rodriguez (Madrid).}

With some modifications of technique, which he has described in his paper, the author has reproduced in rabbits Ewald's classical experiments on the pigeon. He believes that by these experiments he has shown that not only nystagmus, but also the displacement of the eye (forced positions) are produced by the canals. In these experiments it was shown that the effect of stimulating the horizontal canal always includes a vertical displacement of the eye as well as the nystagmus. The "counter rolling" varied according to the direction of the endolymph current; the ampullo-petal movement was associated with a vertical upward displacement, the ampullo-fugal with a downward displacement also in the vertical plane. Control experiments by pressure changes in the utricle appeared to support the contention that these movements are due to stimuli from the horizontal canal, not from the otoliths and maculae.

\section{An Apparatus for the Production of a Standard Speech for Hearing Tests. Helmut Sell (Berlin).}

Sell points out that the most important function of the organ of hearing - the perception of conversational speech-can only be tested by speech sounds. The disadvantage of this method is the difficulty either of maintaining a constant sound-strength of voice, or of weakening the intensity with such a degree of accuracy as to make measurement possible.

To overcome these difficulties Sell has invented the apparatus which he demonstrates. It is essentially an electrical transmission instrument with a special receiver, an amplifier, and a loud-speaker. By this means the spoken voice is reproduced with 100 per cent. of normal clarity as against the i 4 per cent. to 20 per cent. of clearness of the normal telephone speech. By means of a measuring apparatus in the circuit the sound-strength can be observed, and can be kept constant by electrical regulation independent of variations in the speaker's voice. Thus a "standard speech" is produced which can be intensified or weakened at will.

In the discussion, Schwartze pointed out that although the whispered voice could be transmitted as a "total projection" the resonator qualities of the loud-speaker produced important distortions of the raised voice.

\section{Experiments in Minimum Audition and their Relation to the Problem of Middle-Ear Mechanics. A. G. Pohlmann (St Louis).}

I. The ability of the ear, with its phenomenal sensitivity, to operate efficiently under unusual conditions, and to withstand acoustic insult, 


\section{Abstracts}

indicates an insulation which can only be explained on the basis of a full phase interference which operates for all frequencies.

2. The efficient route for air-transmitted sound is from drum membrane through the stapes footplate as first suggested by J. Müller.

3. The functional explanation of $\mathbf{v}$. Helmholtz that the ossicles act as a lever system, which decreases the amplitude and increases the force of the drum membrane vibrations in their propagation to the stapes, is not substantiated.

4. Plus and minus pressures in the air of the external auditory canal decrease the acuity for both air-and bone-transmitted sound.

5. Prolonged bone transmission, like Paracusis Willisi, is apparently not a real phenomenon.

6. The existence of tone islands, as described by Bezold, has not been confirmed.

7. The acuity for bone-transmitted sound is quite variable in individuals with normal air acuity. It also varies in the same individual, depending on the location and possibly also on the direction of the activating source.

8. The lateralisation of bone-transmitted sound in normal individuals is not only dependent on the location of the activating source but also on the intensity of the stimulus, and possibly on the direction of the vibratory thrust.

9. The explanation that the ossicular chain operates more efficiently at low frequencies and less efficiently, or not at all, for high frequencies, is not confirmed.

Io. Localised areas of lowered acuity in the frequency scale have been noted at about 2600 Hertz. They are, however, to be interpreted as filter effects in the sound transmission system, and not in terms of end-organ disability.

I I. The differential diagnosis on the basis of audiometric curves is open to serious objection.

I2. The fork employed for bone transmission acuity should have a frequency from $25^{6}$ to $5^{\text {I } 2}$ Hertz. Below $25^{6} \mathrm{Hertz}$, and especially at 128 , tactile sensations are often confused with audition.

13. Air-tight occlusion of the external auditory canal has but little effect on low frequencies. The blocking effect becomes more pronounced as the pitch rises.

14. The acoustic probe offers a possible means of testing directly for defects in the sound transmission system.

15. The acoustic fan offers a simple method for testing bone transmitted speech. The telephone method, with a potentiometer, shunted across the secondary, connected with a bone activating receiver, is, however, more efficient. 


\section{A Theory of Bone Conduction. A. RejTö (Budapest).}

The two generally accepted theories of bone conduction have been the direct and the osteo-tympanal. There are difficulties in the acceptance of either. In 1914 Rejtö began his experiments using an ivory model of the labyrinth. His conclusions are as follows :-

By the vibration of the skull, wave-motions are induced in the endolymph in the direction of the windows. The movement towards the round window is the same as that produced by the movement of the foot-piece of the stapes for air conduction, but the wave toward the oval window is against the stapes movement. As the elasticity of the two windows is different, the effect of the movement toward the round window is greater, so the resultant of the two movements is in the direction of the round window, just as it is for air-borne sounds, and causes perception of sound in the same way. On this hypothesis it is easy to see why air conduction is better than bone conduction in the normal subject, and an added diagnostic value is given to the shortening of bone conduction.

In the discussion Struycken said that he had never yet seen a single case with physiologically prolonged bone conduction. When the test was made in a perfectly silent environment, we could observe that in our patients there was always to be found some limitation of the bone conduction.

Further Physical Data for a New High-Frequency Treatment for the Improvement of Hearing Capacity. H. MülwerT (Darmstadt).

In this paper, Mülwert deals with a recently published paper of Voss on "A New Method of Physical Treatment of Chronic Deafness, and its Results" (Archiv. f. Ohrenheilkunde, Band cxix., Heft 2), and then discusses the curative action and "extraordinarily strong power of absorption" of high frequency acoustic vibrations.

\section{Researches with a New Model of Electrical Siren ("Otaudion"). O. Kahler and RuF (Freiberg).}

The estimation of the functional condition of the organ of hearing by fixing the auditory threshold can be elucidated by the use of hearing curves. Until now the standard of measurement of the relative tone strength has been the logarithmic decrement of the linear diminished resonance.

This recent advance makes possible the conversion of these logarithmic decrements to reciprocal values of the relative logarithmic terms of phonetic strength. Thereby it is possible to reach a comparison with the relative values of logarithmic sensitivity of hearing capacity. 


\section{Abstracts}

The Labyrinth, Imagination, and the Theory of Einstein.

D. Hellin (Warsaw).

The author points out that imagination is finite. It is limited by our senses, amongst others, by the labyrinth. It does not depend entirely on the will, for we cannot imagine everything that we would wish to imagine; thus the intellect has not absolute control.

Our conception of space and time are dependent on the labyrinth. Every idea based on geometry, of which Einstein's theory is one, has the labyrinth for its source; the semicircular arcs of the labyrinth corresponding to the three co-ordinates of Descartes. The idea of the relations of time and space and the sensation of speed depend on convergence of the ocular axes and on accommodation, which are only a movement of muscles, itself dependent on the labyrinth.

The relativity of space and time in accordance with the views of Einstein is based on labyrinthine function.

\section{$A$ Contribution to the Theory of the Galvanic Vestibular Reaction. \\ G. Dohlman (Upsala).}

In a series of experiments on rabbits the vestibular nerves were exposed within the cranium and there stimulated :-

I. With an intact labyrinth.

2. After labyrinthectomy.

3. After intracranial division of the nerves, central to the vestibular ganglion.

With or without the labyrinth, galvanic stimulation was followed by the normal slow outward deviation of the eyes; with a weak intermittent direct current, or an alternating current, as the means of stimulation, tremors of the eyes were obtained synchronous with the frequency of the current.

After intracranial division, although with current reversal the synchronous tremor was observed, no deviation could be obtained. It follows then that the galvanic labyrinthine reaction does not depend on the labyrinth, but on the vestibular ganglion; unless this is intact, the normal reaction cannot be produced.

\section{The Exclusion of the Subarachnoid Spaces in the Treatment} of Brain Abscess. F. Lemaître (Paris).

After describing the principles and technique of the method previously described by him, the author gave statistics of cases of cerebral abscess treated by him with this method up to date. In 2o cases there were five deaths and fifteen cures. The cured cases 560 


\section{Ear}

were: nine abscesses of the temporo-sphenoidal lobe, two abscesses of the frontal lobe, and four abscesses of the cerebellum.

In the discussion Lund spoke highly of the method. In 18 cases of brain abscess treated in this way he had had $7^{2}$ per cent. recoveries.

\section{Contribution to the Study of Gradenigo's Syndrome. Mangebeira- Albernaz (Campinos, Brazil).}

After a discussion of general aspects of the question and the various pathological explanations suggested, the author described three cases, in each of which the lesion was different. In one case a very large pneumatic cell had nearly completely hollowed out the pyramid of the petrous; in the second case, the syndrome was caused by a foreign body-a revolver bullet-in the groove of the cavernous sinus; in the third case, an abscess of the temporal lobe 5.7 centimetres across with a very thick and resistant capsule.

The lecture was illustrated with photographs and skiagrams.

\section{Demonstration of an Instrument for Drawing the Auricle. Ino KuBo (Fukuoka, Japan).}

Although the shape of the auricle is of considerable interest, both for the criminologist and for the anthropologist, the only method of recording it up to the present has been photography. This takes time, and photographs of the pinna are not always satisfactory. Kubo's apparatus consists of a head-band of ebonite, to which is attached a glass plate fixed over the ear. A sheet of paper is fastened to the plate by the side of the ear. Then with one pen of a two-pen drawing apparatus, also fixed to the head-band, the outline of the ear is traced on the glass; the second pen, automatically following the movements of the first, transfers the drawing to the paper.

\section{The Theory of Oto-Sclerosis. Macleon Yearsley (London).}

The author suggests that oto-sclerosis is entirely due to a general toxæmia of intestinal origin, and that the deafness commences in the cortex of the temporo-sphenoidal lobe. The changes in the labyrinth capsule are trophic in nature and are comparable with those found in rheumatoid arthritis.

The theory is based at present on clinical observations on the author's own cases, aided by the recently published work of MacDonagh on intestinal intoxications.

\section{Frequency of Syphilis in Progressive Deafnesses of Tubo-Tympanic Origin. E. Feuillié and Ruaud (Paris).}

The authors point out the frequency of syphilis in patients suffering from progressive deafness of tubo-tympanic origin, especially in patients under 35 years old. It may be acquired or hereditary and, 


\section{Abstracts}

so the authors believe, acts not by any local lesion, but by the general sclerosing tendency of the disease.

On these grounds they claim that generalised anti-syphilitic treatment will frequently succeed in cases where local measures carried out for several years have completely failed.

\section{A Further Contribution to the Cholesteatoma Problem. BERBERICH (Frankfort).}

Berberich, by experiments on animals, has succeeded in producing cholesteatomata in the uterus and in the stomach as well as in the middle ear. From these experiments he deduces certain points in the pathogenesis of cholesteatoma in man.

Cholesteatoma can originate without any derangement of the physiological processes of pneumatisation, and it can take place entirely independently of any arrest of the process of pneumatisation in the mastoid. He has obtained similar results with cholesteatoma of the nasal accessory sinuses. Here again the process of formation would appear neither to influence, nor to be influenced by, the degree of pneumatisation. In his opinion his results in the great majority of cases confirm the teaching of Wittmaack.

In the discussion, Lemaittre said that, in general, cholesteatoma arose in the unpneumatised mastoid process, since this favoured chronic suppuration. Nevertheless there were exceptional cases.

Voss: That the cases of cholesteatoma formation after acute suppuration in normal completely pneumatised mastoids were not so very unusual; he had himself seen four such cases in a relatively short space of time.

Runge: According to Wittmaack, the principal factor in the production of cholesteatoma was the presence of chronic infection in the mucous membrane. According to Wittmaack's views this would be, as a rule, in the mucous membrane of a compact mastoid, but in exceptional cases it could occur in a normally pneumatised bone.

Berberich, in his reply, said that the point of difference between him and Wittmaack was really very slight, it was only that he was not willing to give support to Wittmaack's teaching in its absolute rigidity.

\section{NOSE AND ACCESSORY SINUSES}

\section{The Indication for a Conservative Operation on the Nasal Septum. W. Wojtschek (Leningrad).}

This operation has been practised for several years in the author's Clinic, and he can now estimate its results and deduce from his experience conclusions as to the indications under which it is preferable. These indications fall under two headings: the first, those concerning 


\section{Nose and Accessory Sinuses}

technique; the second, those which we may describe as the essential indications. As far as the first go, the operation can be done in any case where the technique appears easy to the operator. But the essential indication, the indication for choosing one method or another, depends on the biology of the nasal fossæ. The cases in which the author advises complete removal of cartilage and bone are very rare, for such a method may lead to pronounced deformity of the anterior portion of the nose. The patient's general condition must always be taken into account in this, as in all other nasal procedures.

Nasal Sinus Sepsis as a Cause of Alteration of Character and of Insanity (with illustrations and specimens). P. WATSON-WILliams (Bristol).

Slighter psychic disturbances are frequently the source of unhappiness and definite mental inhibition. More profound toxæmia or the invasion of the blood or lymph spaces afford every gradation of psychosis, from those described as neurasthenia to depressive mania with suicidal impulses or definite delusions. Examples are cited, both of psychosis as well as of certified lunacy, in which cure of the mental defects has followed the diagnosis and operative drainage of sources of focal sepsis in the nose, throat or ear.

Illustrations of specimens are shown to illustrate, post-mortem, chronic invasion of the pituitary body and the meninges, etc., from infected nasal sinuses by low grade pyogenic organisms in patients who were definitely insane.

The influence of para-sinus sepsis on the mentality involves both the intellectual and moral functions, and constitutes a serious social and economic menace which may be alleviated by the recognition and appropriate treatment of the determining cause.

On the Diagnostic Exploration by the Suction Syringe of Posterior Ethmoidal and Sphenoidal Sinuses when Anatomically Irregular. P. Watson-Williams (Bristol).

The author states, that in determining and exactly localising the focus of infection when present in the sphenoidal sinuses or posterior cells the suction syringe has proved most helpful. Investigations in the post-mortem room which he carried out in 1896 led him to introduce a method of puncturing the anterior wall of the sphenoidal sinus and sucking any contained discharge back into the attached sterile syringe, instead of syringing out the sinus by the natural opening. Subsequently he applied the same method to the posterior ethmoidal cells; thus with the suction syringe one can determine the presence or absence of active infective processes in either the maxillary antrum, sphenoidal sinuses and anterior or posterior cells on either side.

The lecture was illustrated with lantern slides and specimens.

$$
5^{6} 3
$$




\section{Abstracts}

Latent Disease of the Maxillary Sinus. W. Mithoefer (Cincinnati).

Latent disease of the maxillary sinus is frequently overlooked. It is often associated with hyperplastic ethmoiditis. It should be suspected if acute involvement of the sinus occurs after operation on the septum or ethmoid. Frequently skiagrams are negative or only slightly opaque; they may be clear if the disease is confined to the recesses. Lavage of the antrum is often negative; it is more satisfactory for diagnosis if this is done early in the morning. Rhinoscopy reveals little unless there is associated ethmoiditis. Often the chief complaint is vasomotor disturbance of the nasal mucosa or post-nasal discharge; this last sign is more frequent if there is an accessory ostium. The best method for the detection of latent antral disease is the instillation of lipiodol with immediate X-ray.

\section{$X$-Ray Examination of the Antrum of Highmore with the Aid of Contrast Material. Ino Kubo (Fukuoka, Japan).}

Kubo finds that the outline of the shadow obtained by using lipiodol is not very clear. He now uses barium sulphate instead, either with water, or as an emulsion of equal parts of barium sulphate and glycerine.

First of all, the antrum is washed out with physiological salt solution-through the accessory ostium where this is present-the last of the fluid is expelled by air, then the antrum is entered with a special cannula and the contrast-fluid slowly injected with a syringe.

Kubo examines the patient with the head in different positions, and with different quantities of fluid in the antrum.

\section{Two Cases of Hydatid Cysts of the Maxillary Sinus. \\ G. Baquero (Corunna, Spain).}

Hydatid cysts of the maxillary sinus are very rare and their formation is subject to the same rules which determine the formation of these cysts elsewhere. They sometimes reach a great size, expanding the sinus and thinning the walls to such an extent as to make them papyraceous. The expansion into the orbit may even compress the globe, and the outer nasal wall may be forced inwards. Apart from the swelling of the jaw there are no symptoms other than a slight degree of neuralgia.

Skiagrams and transillumination show a remarkable transparency; from the inferior orbital margin down to the alveolus appears completely luminous.

Removal should be made through the canine fossa and the incision should be sufficiently large for complete extirpation of the entire cyst.

$$
564
$$




\title{
Nose and Accessory Sinuses
}

\author{
Ozana, Value of Recent Methods of Treatment. \\ F. Bertrán (Madrid).
}

r. The numerous works that have appeared since 1922 on the treatment of Ozæna prove conclusively that not one of them has achieved complete cure.

2. Amongst them all, four only seem to give definite results. They are injections and local treatment by diphtheria antitoxin; treatment by endocrine glands; salicylate of soda in large doses ; and pericarotid sympatheticotomy.

3. The author's own personal experience of these methods has been unsatisfactory, for although he has succeeded in obtaining some improvement in the fotor, dryness, and crusting, such improvement has been transitory.

4. The author emphasises the inadvisability of exaggerated claims on a very small number of cases, especially where, as in sympatheticotomy, the method adopted cannot be free from serious danger. It is only advisable to publish results when the utility and the harmlessness of the treatment has been demonstrated over a considerable number of cases.

\section{A Typical Nasal Disease hitherto Undescribed. S. SRebrny (Warsaw).}

For several years past the author has encountered cases of a nasal condition, unimportant because practically harmless, but with a constant localisation and constant symptoms.

The site of the condition is always the ridge of the nose, generally the bridge, sometimes it extends over the nasal bone. The skin is reddened and painful to touch, but spontaneous pain is slight. The temperature is slightly raised. The condition lasts for several days and passes off without treatment. It is probably an inflammation of the skin and subcutaneous tissue. The periosteum does not appear to be affected.

The patients are nearly always adults; only once has the condition been encountered in a child.

The etiology is uncertain. Several of the patients were arthritic subjects, but not all of them. The nasal mucosa is usually normal. Only in one case was there ethmoiditis with polypi. In one other case the condition was associated with a conjunctivitis. 


\section{Abstracts}

\section{LARYNX}

\section{The Treatment of Laryngeal Stenosis caused by Bilateral Adductor Paralysis. A. RÉrHi (Budapest).}

The medial fixation of the vocal cords is due to the unantagonised action of the adductors. In time the adductors themselves undergo contracture, and it is then impossible to separate the cords without division of the adductors. Réthi's proceeding is as follows :-

A laryngo-fissure is performed, and then an incision is made in the mucous membrane behind the upper part of the arytenoid and carried downwards along the curved lower edge of the cartilage under the vocal process and cord. The arytenoid joint is opened and the transversus and lateralis are exposed with the posticus between them. The transversus and lateralis are divided and removed, care being taken to avoid any injury to posticus. The wound of the mucosa is sutured. Réthi advises removing a strip, 3 to $5 \mathrm{~mm}$. broad, of the redundant mucosa. No plugging should be left in after the first day. The operation should be performed on one side only.

The operation has been performed on four patients, all of whom can now work, run, climb stairs quickly, and speak loudly.

\section{The Sympathetic Innervation of the Larynx. A. LASKIEWIEZ (Poznán, Poland).}

r. The curves obtained show that stimulation of the central end of the sympathetic nerve in the rabbit and the cat has no influence on the form of the curve.

2. Unilateral excision of the ganglia, division of all branches of the nerve, and still more, bilateral section, causes a very marked slowing of the movements of abduction and adduction of the cords.

3. After the intravenous injection in man of $0.0005 \mathrm{grm}$. of ergotamine, a marked slowing of the movements of the cords is observed.

4. As well as the effect on the cord movements there is marked hyperæmia, unilateral or bilateral, of the laryngeal mucosa. The secretion of the laryngeal mucous glands becomes more profuse and viscid.

5. Among the animals operated on the laryngeal image during phonation shows a diminution of the tension of the cords, characterised by incomplete closure of the glottis and a spindle-shaped gap between the cords.

6. On the other hand, in dogs the registration of the movement of the cords shows a resemblance to a functional lesion of the inferior laryngeal nerve in the phase of phonation and of respiration, with relaxation of tension during emission of the voice.

7. In men, after an intramuscular injection of ergotamine (0.00 I to $0.003 \mathrm{grm}$.) there is a diminution of contraction of the cords in the 566 


\section{Larynx}

phase of phonation, and a weakness of muscular tonus. This state was transitory, depending on the extent to which the ergotamine acted on the sympathetic system of the larynx. In the phase of respiration the full mobility of the cords was maintained.

Pericarotid Sympathicectomy with Ligature of the External Carotid as a Palliative Treatment in Inoperable Pharyngo-Laryngeal Cancer. F. Casadesus (Barcelona).

Casadesus has practised this method in several cases of ulcerating carcinoma in this region with intense pain. The relief of pain has been so great that he regards it as a valuable palliative treatment. The sympathetic plexus is stripped for about three centimetres above and below the bifurcation of the common carotid. The external carotid is tied below the origin of the superior thyroid. If any enlarged glands are met with in the course of operation they may be removed. Ulceration and spread of the growth are but little affected by the operation, but the relief of pain is always considerable.

\section{A Phonetic Apparatus for Patients after Laryngectomy.}

F. Casadesus (Barcelona).

The author demonstrated the apparatus that he has been using for ten years after laryngectomy. The apparatus consists essentially of a silver tube containing a vibrating strip of rubber. One end of the tube is connected by a rubber tube and a silver junction to the patient's cannula, while at the other end a small silver tube tipped with rubber is introduced into the mouth. The special point in which this instrument differs from all others of the same kind is an orifice through which the patient can breathe freely while he is not speaking, and which has only to be closed with the thumb of the hand holding the apparatus in order to drive the expiratory current of air across the vibrating strip into the patient's mouth.

The advantages of the instrument are that it can be carried, united to the cannula, without fatigue; the action is good, it is cheap and simple; one hand only is needed to keep it in position, and the inspired air is warmed before reaching the trachea.

\section{Training of the Phonic Respiration in Stammerers. FLATAU and Gutzmann (Berlin).}

The authors point out that all previous methods of treatment of stammering, so far as they have been concerned with respiratory training, have been devoted almost entirely to the regulation of expiratory movements. When inspiration has been dealt with at all the only instruction given has been that it should be short, noiseless, and deep. 


\section{Abstracts}

They regard this regulation of inspiration as the first thing to be aimed at, and point out that it must become habitual, effortless, and involuntary, in order that the patient may acquire the requisite "elasticity" of respiratory movement.

They base their treatment on the use of a mask, which is supplemented by changes of posture while the mask is worn, and by electro-vibration and massage of the abdominal wall, by which indirect but powerful massage of the diaphragm can be brought about.

Treatment is controlled by study of the curves taken by Flatau's pneumograph during speech and at rest. During the early period of treatment the effect of the mask on the frequency of respiration, the heart's action, and the general condition, must be closely observed. At first the mask should only be worn for a few minutes. The period is gradually increased until it can be worn without discomfort for half an hour. Treatment with the mask is given four times a week, and for the first four weeks no other treatment is employed. Their results have been deeper and freer breathing, both thoracic and abdominal, and fuller vocal respiration with normal synchronisation. They refer also to the beneficial psychological effect of the mask treatment.

\section{Intrinsic Carcinoma of the Larynx. Sir St Clair Thomson (London).}

The lecturer discussed the diagnostic and prognostic value of diminished mobility of a vocal cord in carcinoma of the larynx on the basis of $7 \circ$ cases in which he had performed laryngo-fissure.

A diminished mobility of a cord is neither an early sign nor one the presence of which is necessary for the diagnosis. The sign is only to be found in 44 per cent. of cases, and, in general, it is certainly more frequent in infiltrating than in pedunculated or projecting tumours. When it is present it is a valuable sign for the differential diagnosis between innocent and malignant tumours.

It is not only valueless, but can even give rise to error in distinguishing between malignant tumours and tuberculous or syphilitic cases. Its absence is of good omen, but its presence is unfavourable. In every case, taken in connection with the other signs, it is a valuable indication for the choice of methods of removal.

In the discussion, Hajek believed that the problem was not yet solved. He advised serial sections of such removed cords right back to the arytenoid articulation to see whether there might not be in some of these cases an infiltration of the capsular ligament, which could by itself produce a motor disturbance.

Marschik said that fixation of the vocal border could also be produced by damage to the muscles, which was a factor of insecurity in the prognosis. Carcinoma of the vocal border tended to remain stationary for a long time. 


\section{Pharynx}

\section{Dystonic Laryngeal Manifestations in the Extrapyramidal Syndromes. V. FAIRÉn (Saragossa).}

In every voluntary movement there are two phases, initiation and continuation. The first is under the direct control of the pyramidal tract; the second, the "subconscious" or "automatic" phase, is controlled by centres in the subcortical grey matter and their connecting fibres; this group forms the extrapyramidal tract. It follows then that there can be no voluntary movement without the pyramidal tract, but should the lesion be limited to the extrapyramidal group, although movement may take place, the muscle will fail in the static and dynamic tone. Thus the result of pyramidal lesion may be either a paralysis, a contracture, or an increase of reflexes, according to the level of the injury. Lesions of the extrapyramidal tract may be accompanied by rigidity, tremors, choreic movements, and spasms.

These facts, already recognised clinically for the face and limbs, apply also to the larynx, pharynx, and cesophagus in the presence of an extrapyramidal lesion. The author has confirmed this by a series of examinations in the later stages of encephalitis lethargica and of paralysis agitans. He concludes that motor troubles of the larynx with disturbances of the muscle tone are a common feature of these lesions.

\section{PHARYNX}

The Occurrence of Pigment in the Palatal Tonsil. Hans Brünner (Vienna).

The most frequent cause for the appearance of pigment in the tonsil is the resorption of pathological hæmorrhages, inflammatory, circulatory, or traumatic. This pigment, not only the iron-free but also the iron-containing, is found in a typical distribution; in the boundary zone between the lymphatic tissue and the capsule (the "hämolytische grenzzone" of Schmidt), in the intrafollicular tissue, and on the edges of the follicles.

In the majority of cases the quantity of pigment is small, but still it can attain to a considerable amount in severe cases of chronic inflammatory change in the neighbourhood of the tonsil, or in the more serious blood diseases. It is doubtful whether these hæmolytic processes occur in the tonsil under normal conditions, but it is possible to demonstrate them clearly in pathological states. In a series of experiments on rabbits Brünner has demonstrated, after intravenous injection of saccharated oxide of iron, that iron is deposited in the cells of the walls of the tonsillar veins, and in the walls of the capillaries, whereas the lymphatic tissue, in spite of its copious reticular cells, usually does not retain any of it. It appears, 


\section{Abstracts}

too, that the vascular endothelium of the tonsil, like the endothelium of the lymphatic glands, is impermeable to colloidal iron; but, unlike the lymphatic gland endothelium, the vascular endothelium is capable of storing iron to a high degree. It is now known that cells that retain iron are as a general rule also affected in disorders of the iron metabolism. From these observations it would appear that the tonsil must play an important part in the iron metabolism.

In the discussion, Keleman said that for many years he had laid stress on the fact that on the grounds of general relationship the tonsil belonged to the reticulo-endothelial system, as he had shown in his work on the action of the tonsil substance on the rate of acceleration of blood coagulation.

Berberich agreed with Brünner on the ground of the results of his own experiments. It was possible in man, in cases of pernicious anæmia and hæmochromatosis, to demonstrate the same typical sites of iron deposit that Brüner had shown.

\section{Diathermy in Malignant Growths of the Upper Air and Food Passages. Norman Patterson (London).}

The lecturer dealt principally with diathermy in the treatment of carcinoma of the tongue and cheek. He pointed out the difference in prognosis in superficial carcinoma of the tongue and in cases with infiltration and glandular metastases; most of the cases which he had treated had belonged to the second group. His experience was in agreement with other observers as to the bad prognosis in cases where the base of the tongue was attacked; in such cases he was inclined to advise radium rather than diathermy.

In discussing the question as to whether preliminary ligation of the external carotid was advisable in cases where exposure of the remaining portions of an organ made secondary hæmorrhage a possibility, the lecturer said that he thought that in some cases it was reasonable to tie the external carotid on both sides. He brought forward reasons for and against removing lymphatic glands two or three weeks before the diathermy operation, and advocated this procedure.

He criticised the orthodox treatment of carcinoma of the floor of the mouth with invasion of the periosteum of the lower jaw, and advised diathermy in such cases. He also described the operative method which he had devised for carcinoma of the cheek (vide Lancet, I927, ist October, p. 703). On the whole he regarded diathermy as the most valuable method at our disposal for the treatment of these cases. In some cases radium was preferable, and there 'was now a field for combined treatment by the two methods.

The paper was illustrated by an epidiascope demonstration of case results. 


\section{Pharynx}

Some Rare Complications of Angina. S. SREBRny (Warsaw).

The author quoted the following cases of complications associated with acute pharyngeal conditions:-

I. Two cases of hæmorrhage in patients previously healthy: a boy of 16 and a man about 40.

2. An inflammation of the Tendo Achillis in a young woman with no trace of any rheumatic condition, in the course of a peritonsillar abscess.

3. Two cases of acute thyroiditis following a pharyngeal angina.

\section{Pathological Appearances of the Larynx and Pharynx in the Leukamias and Pseudoleukamias. V. FAIRÉn (Saragossa).}

The leukæmias are now regarded as general systemic diseases of myeloid or lymphoid tissues. For a long time it was believed that hyperplasia of these tissues always caused quantitative modifications of the blood composition. It is now recognised that there are leukæmic conditions in which there is a qualitative variation from the normal blood picture without any increase in the total leucocyte count. The pharynx has itself so abundant a supply of lymphoid tissue, and is in such close connection with the lymphatics of the neck, that frequently it shows changes both in the true and the false leukæmias. In Hodgkin's disease cases are seen in which the tonsil undergoes an enormous hypertrophy which finishes by taking on typically malignant characters.

The author's conclusions are as follows:-

I. Some cases of leukæmia are associated with diffuse or circumscribed infiltrations of the pharynx.

2. In the pseudoleukæmias, especially in lymphadenoma and Hodgkin's disease, there are cases in which the tonsil undergoes an increase of size and infiltrations indistinguishable from those found in malignant disease.

3. Ulceration, though frequent in the pseudoleukxmias, is rare in the true leukæmias.

4. In both types, cases with tonsillar invasion are rapidly fatal.

\section{MISCELLANEOUS}

\section{Blood Transfusion in Oto-Rhino-Laryngology. Gamalia and Michon (Nancy).}

In a series of their own cases of hæmorrhage following operations on the nose and tonsils that had endangered the patient's life, and had resisted the usual medical treatment, rather than have resource to any mutilating operation the authors had tried blood transfusion, 


\section{Abstracts}

with results so satisfactory that they had thought them worthy of presentation.

The paper includes a general discussion of the principles of transfusion, with special application to the regions of throat and ear surgery, and the exact indications for its use. The authors are strongly in favour of the further use of a method of treatment which they have found very valuable.

\section{Acute Sinusitis and Mastoiditis treated by the Autophylactic Method of Feuillié. L. RuAud (Paris).}

The autophylactic method which Feuillie has applied to many general acute infections is also of use in the treatment of acute sinusitis and acute mastoiditis. Ruaud has used this method for acute sinusitis of the antrum, ethmoid and frontal, and in the great majority of cases has found a disappearance of cedema and pain in the first 24 hours.

In ten cases of acute mastoiditis with indications for operation the same method was applied, with the result that in eight of them signs of infection rapidly disappeared and the patients recovered without operation.

Lastly, in a patient with acute polysinusitis and acute left mastoiditis with indications for operation, the method saved the patient from operation, which, considering his general bad condition, would have involved grave risk. In Ruaud's opinion, by this method it is possible to obtain a cure in many cases in which up to now an operation would have been necessary.

\section{Autophylactic Therapy in Auto-Rhino-Laryngology. E. Feuiluí́ (Paris).}

When a condition, whether chronic or acute, shows no tendency to reach a spontaneous cure, autophylaxy can be assisted by a variety of medical measures, of which the most effectual are those which act by leucotherapy and crasitherapy. For acute conditions such as accessory sinusitis, mastoiditis, otitis, the phlegmons, etc., daily intramuscular injections of colloidal silver are advised, with cachets of calomel every other day. For chronic conditions, whether syphilis be present or not, mercury or bismuth treatment is used.

The author claims by this method to have obtained many cures, and to have considerably reduced the number of local treatments and surgical interventions. 